\title{
Cardiac catherization in Austria
}

\section{Results from the Austrian National Cardiac Catheterization Laboratory Registry (ANCALAR) 2012-2018}

\author{
Volker Mühlberger · Lalit Kaltenbach · Katie Bates (iD · Hanno Ulmer for Austrian National Cardiac Catheterization \\ Laboratory Registry (ANCALAR), Österreichische Kardiologische Gesellschaft (ÖKG)
}

Received: 13 February 2019 / Accepted: 17 December 2019 / Published online: 29 January 2020

(c) The Author(s) 2020

\begin{abstract}
Summary
Background Cardiac catheterization is one of the most widely performed cardiac interventional procedures worldwide. The Austrian National Catheterization Laboratory Registry (ANCALAR), started in 1992, collects annual data on cardiac catheterization in Austria. The registry enables in-depth understanding of the dynamics of cardiac catheterization procedures and their use across 34 cardiac catheterization laboratories in Austria.

Methods Data from ANCALAR on cardiac catheterization including the latest data for 2017, voluntarily provided by centers with cardiac catheterization laboratories, were analyzed. Where possible, international comparisons in therapeutic and interventional cardiac procedures are made with Switzerland and Germany.

Results Internationally, Austria ranks alongside the top countries in Europe. Whilst the number of people undergoing routine percutaneous coronary interventions (PCI) remains stable, complex and acute interventions are increasing year by year in Austria.

Conclusion Evidence from ANCALAR revealed that Austria is another example of the difficulties of weighing current guidelines with new emerging evidence
\end{abstract}

Electronic supplementary material The online version of this article (https://doi.org/10.1007/s00508-019-01599-4) contains supplementary material, which is available to authorized users.

\section{Prof. V. Mühlberger}

Ordination Professor Mühlberger,

Innrain 46, 6020 Innsbruck, Austria

\section{Kaltenbach $\cdot$ K. Bates $(\bowtie) \cdot$ H. Ulmer}

Department of Medical Statistics, Informatics und Health

Economics, Medical University of Innsbruck, Schöpfstr.

41/1, 6020 Innsbruck, Austria

katie.bates@i-med.ac.at and resulting real-life clinical practice in the dynamic world of interventional cardiology.

Keywords Percutaneous coronary intervention . Coronary angiography $\cdot$ Cardiology $\cdot$ Austria

\section{Introduction}

Cardiovascular diseases, in particular coronary artery disease (CAD), remain the world's leading cause of mortality and morbidity [1]. The gold standard for diagnosis and intervention in $\mathrm{CAD}$ remains cardiac catheterization, angiography and percutaneous coronary intervention (PCI) [2]. Cardiac catheterization is one of the most widely performed cardiac interventional procedures worldwide, it is a high-cost, highrisk procedure and its history has been characterized by rapid advances in both technique and technology [3]. For such a dynamic field of medicine, registries provide a means to monitor adherence to international guidelines, standards of care and enable benchmarking at the subnational and national level [4].

The Austrian National Catheterization Laboratory Registry (ANCALAR) is an observational registry that collects data on cardiac catheterization in Austria. Data have been collected annually since 1992, data are submitted on a voluntary basis by hospitals performing interventional procedures in Austria, the data are then centrally processed and analyzed. The ANCALAR is a valuable resource, revealing the everyday practice of interventional cardiology in Austria and enabling international comparisons.

With new data from 2017 now available, trends in cardiac catheterization in Austria from 2012-2017 are described, contextualised with reference to both international treatment guidelines and international comparisons with Germany and Switzerland. 
Table 1 Cardiac catheterization Laboratory structure in Austria 2011-2017

\begin{tabular}{|c|c|c|c|c|c|c|c|}
\hline Year & 2011 & 2012 & 2013 & 2014 & 2015 & 2016 & 2017 \\
\hline Number of centers & 36 & 34 & 34 & 34 & 34 & 34 & 34 \\
\hline Number of tables & 49 & 50 & 50 & 52 & 53 & 53 & 54 \\
\hline Number of physicians for diagnostics only ${ }^{a}$ & 243 & 261 & 272 & 271 & 291 & 309 & 304 \\
\hline Number of physicians for diagnostics and $\mathrm{PCl}^{\mathrm{a}}$ & 214 & 222 & 226 & 238 & 250 & 250 & 262 \\
\hline
\end{tabular}

\section{Data and methods}

Data on diagnostic and interventional cardiac procedures in 2017 in the Austrian National Catheterization Laboratory Registry (ANCALAR) were used. In line with previous research, data were compared to the national cardiac catheterization registries of Germany and Switzerland [5-10].

ANCALAR is a voluntary, financially independent registry, maintained co-operatively by participating performing hospitals in Austria, coordinated by its initiator, Professor Mühlberger. The data are securely stored centrally and processed by the Department for Medical Statistics, Informatics and Health Economics at the Medical University Innsbruck. Whilst participation in the registry is voluntary, all hospitals providing interventional cardiac procedures in Austria participate, thus the data represent all cardiac intervention in Austria [5, 6].

Since 1992, the registry has collected over 90 parameters concerning cardiac catheterization, without interruption. Data are collected in accordance with the cardiology audit and registration data standards (CARDS) [11, 12]. Data collection tools are reviewed annually by the Interventional Cardiology working group of the Austrian Cardiology Society at its autumn meeting and, where necessary, updated. To ensure comparability over time only minimal, necessary modifications are made, for example when changes in treatment guidelines or available medical devices occur [5, 6, 11-17]. All changes are made collaboratively, in cooperation with the participating centers, with updates to methods published in subsequent annual reports. Data collection tools and indicator definitions are available on the ANCALAR study homepage: https://iik.i-med.ac.at/ [11].

Each center collects and summarizes their data annually, at the end of the year. During each calendar year, centers are visited or contacted in order to both perform audits and maintain working relationships. Quality control mechanisms have meant thatin Austria $100 \%$ of CathLabs submit data to the registry each year. Once $75 \%$ of clinics have completed the data entry, the remaining clinics are contacted personally (inperson meeting, telephone call or individual email), so far up to four repeat personal contact attempts have been required. Mass email follow-up, as has also been documented in Switzerland, has limited utility [7].

Using new data from 2017, trends in key cardiac catheterization indicators in Austria, including acute
Fig. 1 Cumulative numbers of reported diagnostic coronary angiographies (CA) performed in 2017 from the $n=34$ catheterization laboratories in Austria by date of report during 2018 in the national Excel sheet until 8 August 2018 $(n=56,515)$

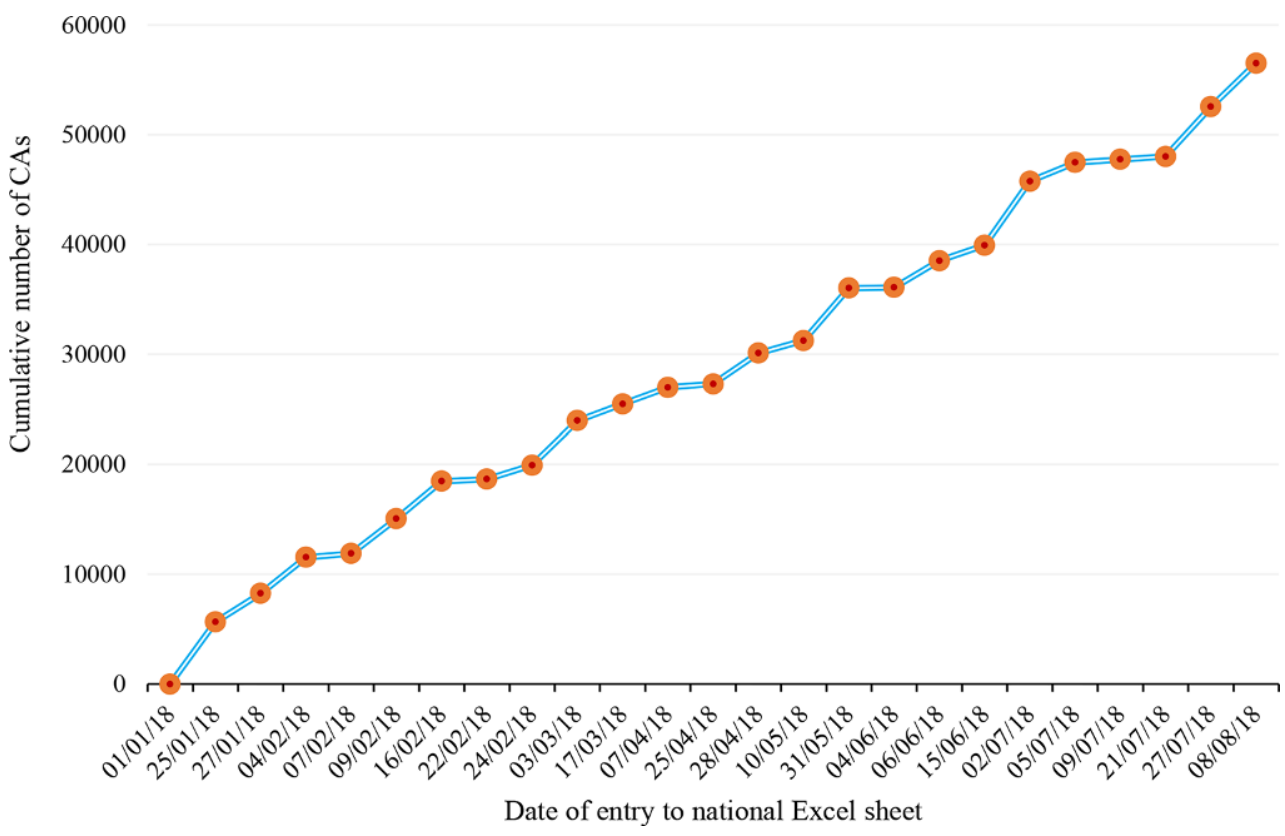


Table 2 Cardiac catheter diagnostics in Austria 2012-2017 across all reporting centers with available data. (Source: Austrian Questionnaire "diagnostics and related procedures") [11]

\begin{tabular}{|c|c|c|c|c|c|c|}
\hline Year & 2012 & 2013 & 2014 & 2015 & 2016 & 2017 \\
\hline Diagnostic coronary angiography (CA) & 53,064 & 54,566 & 56,062 & 54,853 & 56,750 & 56,515 \\
\hline Mortality CA overall (\%) & $\begin{array}{l}76 \\
(0.14)\end{array}$ & $\begin{array}{l}61 \\
(0.11)\end{array}$ & $\begin{array}{l}59 \\
(0.11)\end{array}$ & $\begin{array}{l}61 \\
(0.11)\end{array}$ & $\begin{array}{l}59 \\
(0.10)\end{array}$ & $\begin{array}{l}25 \\
(0.04)\end{array}$ \\
\hline CA without shock due to infarction & 7969 & 7769 & 9467 & 9210 & 9453 & 9263 \\
\hline Mortality CA without shock (\%) & $\begin{array}{l}29 \\
(0.36)\end{array}$ & $\begin{array}{l}23 \\
(0.30)\end{array}$ & $\begin{array}{l}23 \\
(0.24)\end{array}$ & $\begin{array}{l}20 \\
(0.22)\end{array}$ & $\begin{array}{l}27 \\
(0.29)\end{array}$ & $\begin{array}{l}12 \\
(0.13)\end{array}$ \\
\hline CA with shock due to infarction & 520 & 434 & 505 & 474 & 429 & 358 \\
\hline Mortality CA with shock (\%) & $\begin{array}{l}27 \\
(5.19)\end{array}$ & $\begin{array}{l}25 \\
(5.76)\end{array}$ & $\begin{array}{l}28 \\
(5.54)\end{array}$ & $\begin{array}{l}19 \\
(4.01)\end{array}$ & $\begin{array}{l}15 \\
(3.50)\end{array}$ & $\begin{array}{l}11 \\
(3.07)\end{array}$ \\
\hline Myocardial infarction as complication & 31 & 28 & 25 & 32 & 32 & 8 \\
\hline With new $Q$-wave & 9 & 9 & 3 & 0 & 0 & 1 \\
\hline Defined by troponin or CK & 24 & 23 & 6 & 32 & 28 & 4 \\
\hline Nonfemoral (radial) approach & 12,055 & 18,441 & 20,735 & 27,673 & 31,850 & 34,627 \\
\hline Switch to femoral during procedure & - & - & - & 1500 & 1702 & 1901 \\
\hline Local radial artery complications & - & - & - & - & - & 112 \\
\hline Reversible neurological complications & 33 & 41 & 37 & 48 & 37 & 44 \\
\hline Irreversible neurological complications & 3 & 13 & 9 & 6 & 10 & 6 \\
\hline Vascular peripheral complication & 277 & 309 & 264 & 223 & 192 & 113 \\
\hline With surgery or transfusion & 56 & 41 & 49 & 42 & 28 & 25 \\
\hline With local injection of thrombin & 77 & 115 & 105 & 75 & 59 & 34 \\
\hline Adverse reactions to contrast media & 70 & 70 & 86 & 204 & 201 & N.A. \\
\hline Left ventricular angiography & 18,163 & 18,572 & 11,834 & 12,628 & 11,646 & 10,941 \\
\hline Right heart catheterization & 3142 & 3288 & 3515 & 3401 & 3489 & 3368 \\
\hline $\begin{array}{l}\text { Striking differences in italics } \\
\text { CK Creatine (Phospho)Kinase } \\
\text { "-" data not available }\end{array}$ & & & & & & \\
\hline
\end{tabular}

and non-acute PCI use, treatment of ST-elevation myocardial infarction (STEMI), puncture techniques and complications, re-interventions for chronic stent restenosis (REDOs), use of innovative medical devices, electrophysiology and transarterial aortic valve procedures (TAVI) are assessed [11, 18].

Indicators are constructed in line with the published ANCALAR methods, definitions of procedures presented in this paper are available in Supplementary Table $1[5,6,11]$. In brief, indicators are constructed using data pooled across all performing clinics and do not exclude cases with missing data in the numerator where denominator data are complete, thus underestimates are likely. To give a more accurate picture of what is happening in Austrian CathLabs, indicators are also constructed using pooled data from subsets of clinics where data are complete.

International comparisons are made with Switzerland and Germany using pooled data from PCI clinics in each respective country, diagnostic coronary angiographies (CA), TAVI and glycoprotein (GP) blockers are compared using both absolute numbers, and crude rates per one million inhabitants, in line with conventional methodology [7-11, 17-21].

\section{Results}

All 34 PCI clinics operating since 2012 in Austria submitted data to the registry for 2017, with a total of 54 CathLab tables between them, in 2017 (Table 1). In 2017, 56,515 CAs were reported (Fig. 1; Table 2).

\section{International context}

In Austria and Switzerland, the absolute numbers of CA are comparable and varied between 2016 and 2017 whilst Germany has consistently higher rates of CA. The PCI/CA ratio increased, with 40.2 of all CAs resulting in PCI in 2016 whilst $42.1 \%$ resulted in PCI in 2017 in Austria, comparable with Germany and lower than Switzerland (Table 2; Figs. 2, 3 and 4).

For CA and PCI rates, Austria places just under the top nations in Europe; Austria is in the middle range for TAVI (115 per million population in 2017), with the rate of TAVI per 1 million population increasing year by year (Fig. 5; [17, 21]) Austria began reducing the use of GP blockers years before guidelines reacted to new evidence and at the same time Switzerland stopped counting these cases in their registry (Fig. 6). In contrast, reduction in the use of balloon pumps and catheter thrombectomies in Austria has been protracted (Table 3 and 4; [13-18]). 
Fig. 2 Number of diagnostic coronary angiographies per million inhabitants in Austria (AU), Switzerland $(\mathrm{CH})$ and Germany (D) during the years until 2017 and Germany until 2016 [1-11]. (Source: [18, pp 14])

Fig. 3 Number of percutaneous coronary interventions ( $\mathrm{PCl}$ on the $y$-axis) per million inhabitants (EW) in Austria (AU), Switzerland $(\mathrm{CH})$ and Germany (D) during the years until 2017, and Germany (D) until 2016 [1-12]. (Source: [18, pp 14])

Fig. 4 Number of diagnostic electrophysiology, electrophysiological ablations and device implantations in Austrian Cardiac Catherization Laboratories 2003-2017.

(Source: [18, pp 23])
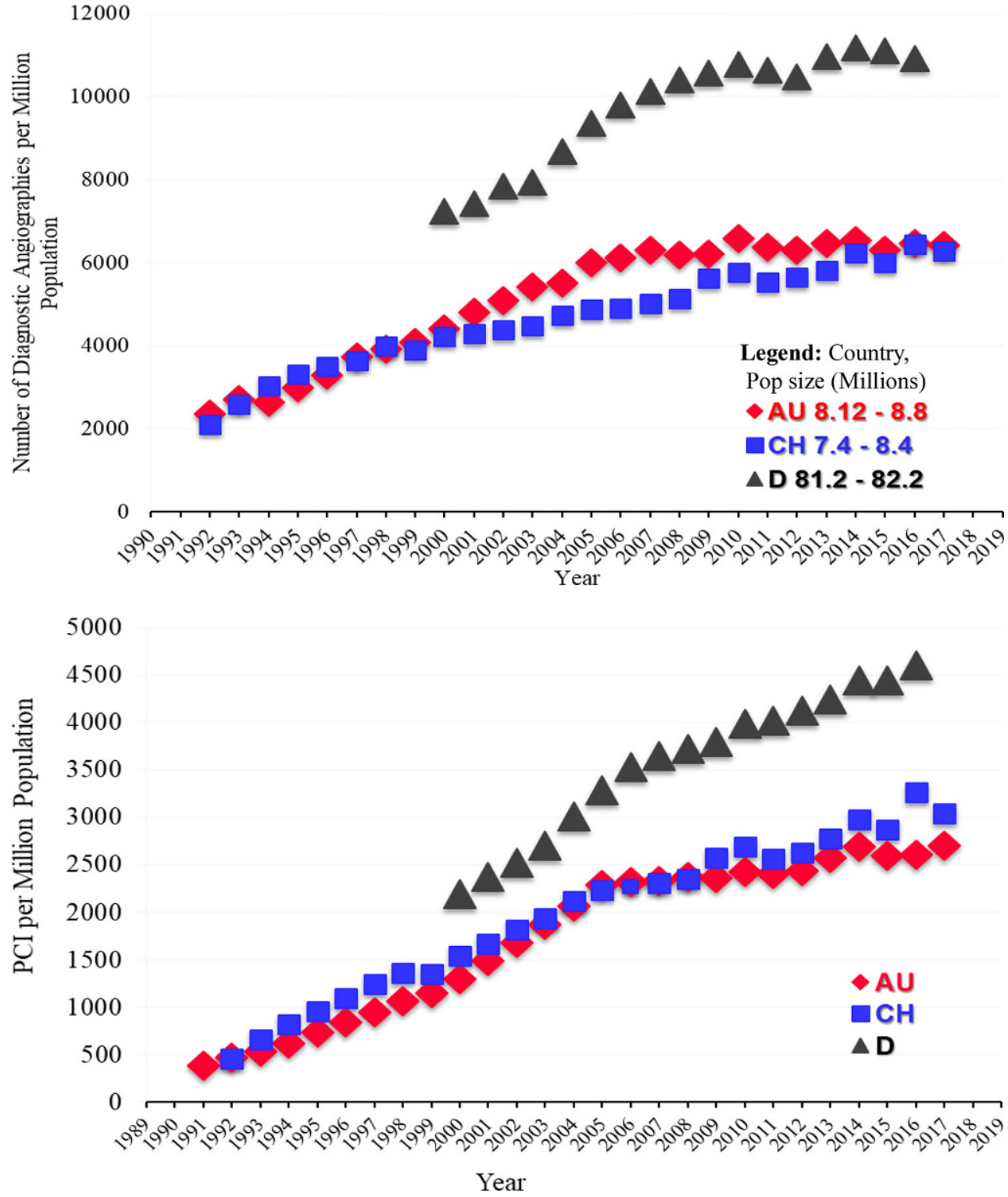

4500

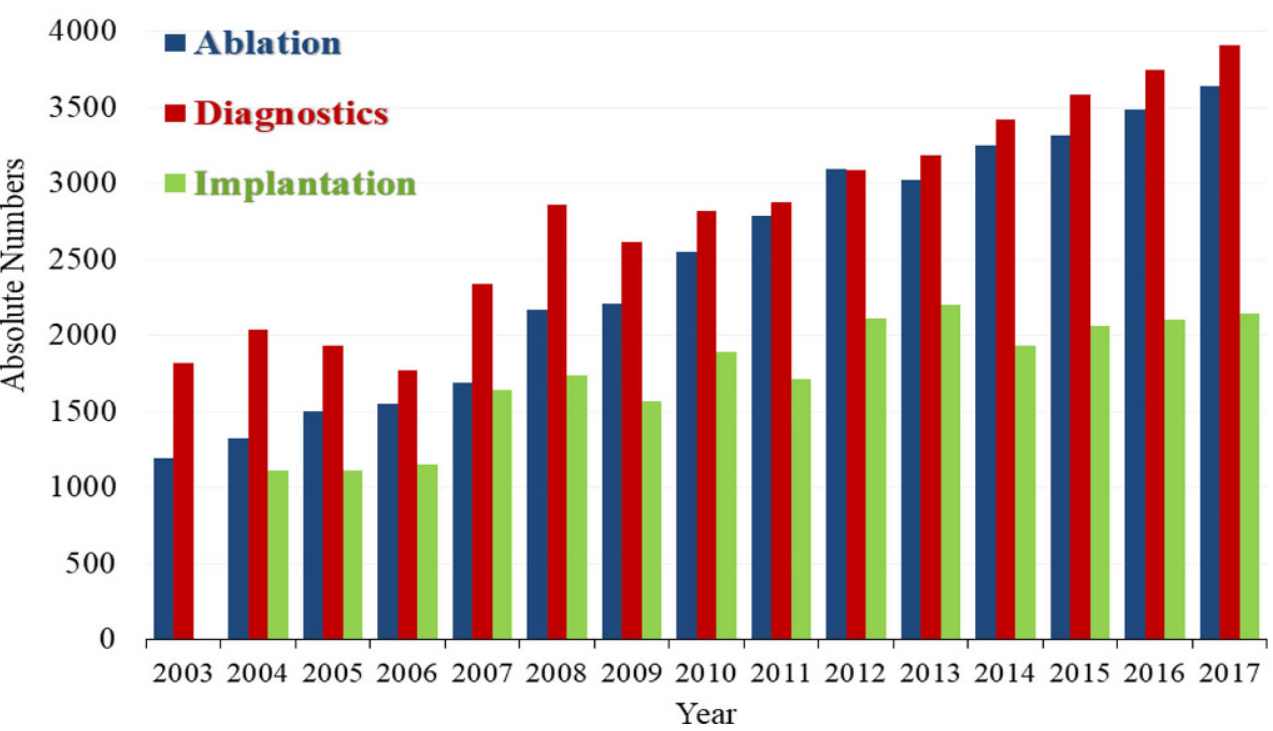


Fig. 5 Absolute number of transcatheter aortic valve implantations (TAVI) in Austria during the years 2007-2017 and number of TAVI interventions in Switzerland during the years 2009-2016 [1-9]. (Source: [18, pp 24])

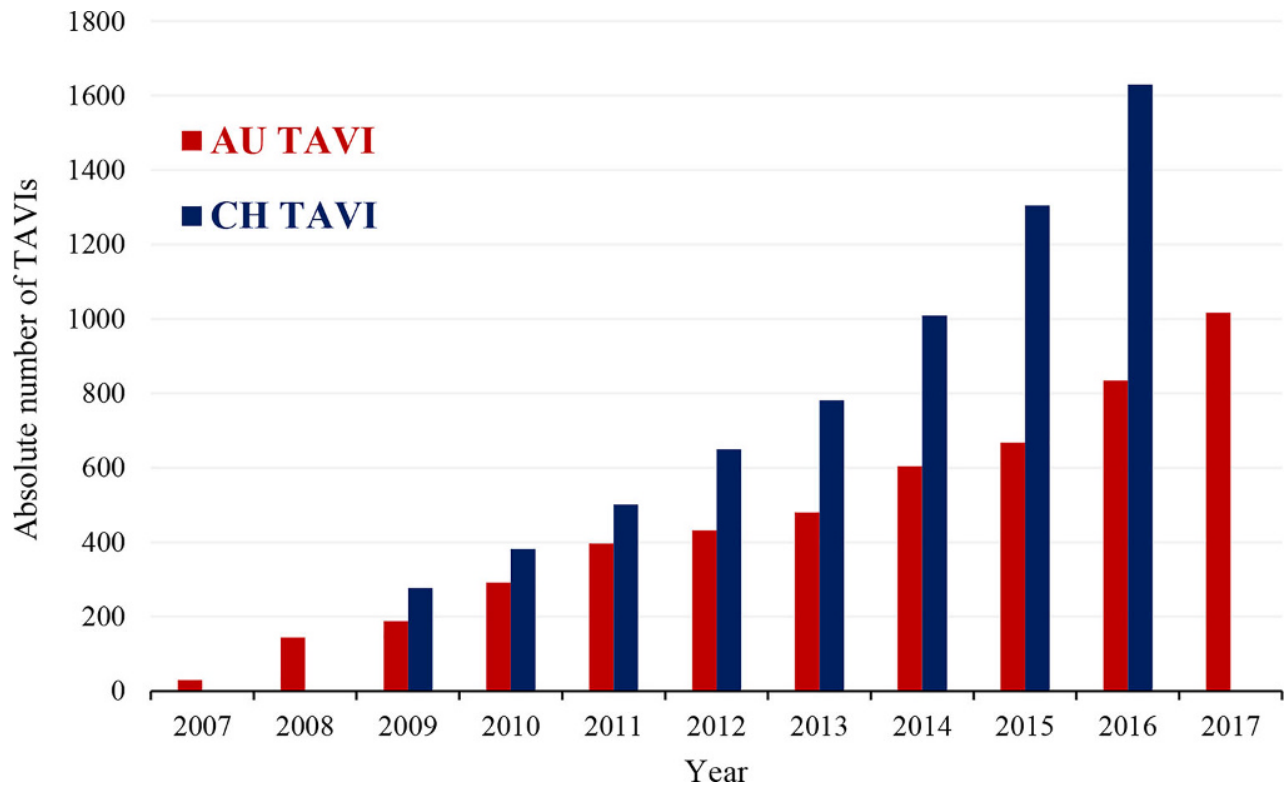

Fig. 6 Percentage (\%) of cases treated with glycoprotein Ilb/IIla receptor blockers (GP-blocker) per $\mathrm{PCl}$ in Austria (AU; 1997-2017) and in Switzerland $(\mathrm{CH} ; 1997-2009)$ and percentage (\%) of cases treated with direct thrombin inhibitors (AU-TI) during $\mathrm{PCl}$ in Austria (AUTI; 2005-2017). [1-13]. (Source: [18, pp 22]


-AU -GP Blocker

口CH -GP Blocker

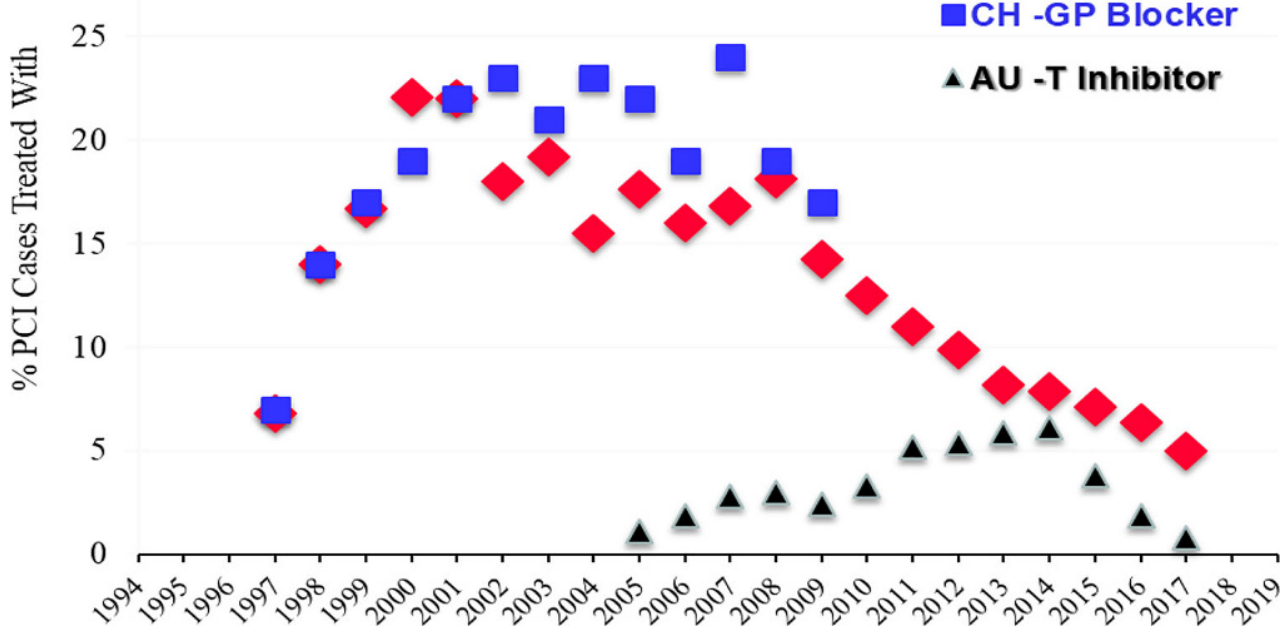

\section{Trends in acute and non-acute PCl use in Austria}

The number of elective non-acute PCI has plateaued, with the number of cases in 2017 ( $n=14,255)$ remaining almost identical to 10 years ago $(n=14,254$ cases in 2006) (Table 5; $[18,19]$ ); however, the number of patients undergoing non-routine and/or acute PCI (which interrupt daily planned PCI) is increasing year by year (Table 6). In 2017, mortality rates for all acute PCI was $1.64 \%$, although this value is based on the pooled analyzes of all centers, including those with missing data in the numerator, and thus is likely an underestimate of the true PCI mortality rates across Austria.

An increase of complex and acute interventions is evidenced by the increase in STEMI-PCI (Table 3 and 6) to $20.0 \%$ of all PCI (in reporting centers) in 2017 (Supplementary Table 2). The number of ad hoc multivessel PCI increased to $20.8 \%$ of all PCI in
2017 (Table 3). There is also an increase of PCI in bifurcation of large side branches from $6.7 \%$ (2012) to $12.4 \%$ (2017) and for left main stents from 2.0\% (2011) to $3.3 \%$ (2017, Table 6$)$.

Currently 21 centers fulfil the criterion of more than 36 STEMI PCI cases per year, down from a peak of 24 in previous years [20]. PCI for ongoing STEMIs have increased $32 \%$ since 2012, emergency surgery after PCI also increased, with some fluctuations, although n's are small so this result should be interpreted with caution (Table 3). Mortality due to emergency surgery post PCI has more than doubled since 2012 to $11.4 \%$ in 2017 (Table 3), although again n's are small (4 deaths in 35 emergency surgeries) and the definition of emergency surgery has become broader.

The incidence of major bleeding relative to all bleeding complications is declining, especially in acute PCI (from $34.0 \%$ in 2010 to $15.8 \%$ in 2017) (Supplementary Table 2). Use of glycoprotein IIb/ 
Table 3 Percutaneous coronary interventions (PCI) and related procedures in Austria 2012-2017

\begin{tabular}{|c|c|c|c|c|c|c|}
\hline Year & 2012 & 2013 & 2014 & 2015 & 2016 & 2017 \\
\hline $\begin{array}{l}\text { Intracoronary diagnostic device without PCl (cases) e.g. FFR, IVUS, } \\
\text { OCT }\end{array}$ & - & - & - & 1808 & 2532 & 2148 \\
\hline $\mathrm{PCl}$ (cases) therapeutic interventions & 20,543 & 21,698 & 23,044 & 22,538 & 22,837 & 23,808 \\
\hline PCl for acute situation OR ongoing infarction & 7026 & 7148 & 7791 & 8084 & 8612 & $9553 \uparrow$ \\
\hline $\mathrm{PCl}$ for ongoing STEMI & 3476 & 3546 & 3959 & 3943 & 4070 & $4581 \uparrow$ \\
\hline Bifurcation $\mathrm{PCl}$ with large side branch & 989 & 1081 & 1175 & 1454 & 1922 & 1920 \\
\hline Multivessel PCI (in one session) & 3231 & 3094 & 4309 & 4300 & 4519 & 4478 \\
\hline $\mathrm{PCl}$ during diagnostic study (ad hoc) & 17,559 & 16,085 & 18,596 & 16,652 & 16,313 & $16,195 \downarrow$ \\
\hline Radial/brachial approach (non-femoral) during PCl & 4727 & 6664 & 9104 & 9713 & 12,551 & $13,468 \uparrow$ \\
\hline Switch (crossover) to femoral during or before $\mathrm{PCl}$ & - & - & 474 & 479 & 794 & $1017 \uparrow$ \\
\hline Local radial artery complication & - & - & - & - & - & 77 \\
\hline Infarction as complication (by any definition) & 82 & 78 & 80 & 114 & 174 & 122 \\
\hline latrogenic left main artery dissection & 18 & 16 & 24 & 20 & 14 & 27 \\
\hline Emergency surgery after $\mathrm{PCl}$ and/or $\mathrm{CA}$ & 19 & 17 & 22 & 19 & 27 & $35 \uparrow$ \\
\hline In-hospital death after $\mathrm{PCl}$ & 170 & 185 & 243 & 205 & 239 & 180 \\
\hline In-hospital death despite emergency surgery post $\mathrm{PCl}$ & 1 & 1 & 1 & 1 & 5 & 4 \\
\hline Number of STENT cases: & 18,577 & 19,995 & 21,008 & 20,646 & 21,257 & $22,417 \uparrow$ \\
\hline Drug eluting stents (cases) (DES) & 15,778 & 17,010 & 19,451 & 19,735 & 20,509 & $21,565 \uparrow$ \\
\hline Drug eluting balloon (DEB) (cases) & 723 & 847 & 782 & 937 & 1169 & 1090 \\
\hline Biodegradable vascular scaffolds (BVS) (aka Biostent) & 113 & 1019 & 1693 & 1058 & 593 & $112 \downarrow$ \\
\hline Left main stents & 402 & 452 & 473 & 522 & 636 & 636 \\
\hline Multiple stents (cases) & 5360 & 5668 & 8021 & 6680 & 7496 & 6933 \\
\hline $\mathrm{PCl}$ for in stent restenosis & 687 & 801 & 617 & 814 & 794 & 782 \\
\hline $\mathrm{PCl}$ due to chronic hyperplasia & 329 & 505 & 470 & 559 & 639 & 613 \\
\hline $\mathrm{PCI}$ due to very late chronic stent thrombosis & 82 & 102 & 94 & 103 & 71 & 65 \\
\hline \multicolumn{7}{|c|}{$\begin{array}{l}\text { Original questionnaire of the European Society of Cardiology (ESC) [19] } \\
\text { cases; } n \text { pooled analysis } \\
\text { Striking differences in italics. Striking changes from } 2016 \text { to } 2017 \text { are indicated with directional arrows } \uparrow \text { (increase) } \downarrow \text { (decrease) } \\
\text { "-" data not available } \\
\text { FFR Fractional Flow Reserve, IVUS Intravascular Ultrasound, OCT Optical Coherence Tomography, STEMI ST-Elevation Myocardial Infarction, CA Cardioangiogra- } \\
\text { phy }\end{array}$} \\
\hline
\end{tabular}

Table 4 Percutaneous CathLab interventions and related procedures in Austria (2012-2017)

\begin{tabular}{|c|c|c|c|c|c|c|}
\hline Year & 2012 & 2013 & 2014 & 2015 & 2016 & 2017 \\
\hline Rotablator & 312 & 369 & 418 & 373 & 312 & 300 \\
\hline Catheter thrombectomy (clot catcher/remover) & 1848 & 1799 & 1606 & 1317 & 1077 & $891 \downarrow$ \\
\hline Intracoronary pressure registration ("fractional flow reserve" (FFR)) & 2182 & 2547 & 2524 & 3153 & 3631 & 3668 \\
\hline FFR decision with adenosine and/or & - & - & - & - & 3220 & $3164 \downarrow$ \\
\hline FFR decision without adenosine (= iFR) & - & - & 19 & 64 & 411 & $604 \uparrow$ \\
\hline PCl for chronic total occlusion (CTO) & 637 & 589 & 559 & 790 & 782 & 808 \\
\hline Intracoronary ultrasound (IVUS) & 816 & 783 & 711 & 670 & 808 & 755 \\
\hline Intra-aortic balloon pump during $\mathrm{PCl}$ & 121 & 87 & 82 & 69 & 37 & $53 \uparrow$ \\
\hline $\begin{array}{l}\text { Other devices (e.g. mechanical circulation support, protection device) in } \\
\mathrm{PCl}\end{array}$ & 53 & 22 & 118 & 102 & 18 & $30 \uparrow$ \\
\hline Platelet glycoprotein IIb/llla antagonist & 2025 & 1775 & 1815 & 1597 & 1467 & $1201 \downarrow$ \\
\hline Direct thrombin inhibitor in PCl & 1110 & 1277 & 1406 & 858 & 439 & $198 \downarrow$ \\
\hline Optical coherence tomography (OCT) & 350 & 570 & 503 & 580 & 707 & 638 \\
\hline Alcohol ablation for septal hypertrophy (PTSMA) & 8 & 14 & 11 & 6 & 13 & 9 \\
\hline \multicolumn{7}{|c|}{$\begin{array}{l}\text { Special techniques, Original questionnaire of the European Society of Cardiology (ESC) [19] } \\
\text { cases; } n \text { pooled analysis } \\
\text { Striking differences in italics. Striking changes from } 2016 \text { to } 2017 \text { are indicated with directional arrows } \uparrow \text { (increase) } \downarrow \text { (decrease) } \\
\text { "-" data not available } \\
P C / \text { percutaneous coronary intervention }\end{array}$} \\
\hline
\end{tabular}


Table 5 Cardiac catheter interventions in Austria 2012-2017

\begin{tabular}{|c|c|c|c|c|c|c|}
\hline Year & 2012 & 2013 & 2014 & 2015 & 2016 & 2017 \\
\hline Nonacute $\mathrm{PCl}$ & 13,517 & 14,550 & 15,253 & 14,454 & 14,225 & 14,255 \\
\hline Mortality PCI non-acute overall (\%) & $\begin{array}{l}14 \\
(0.10)\end{array}$ & $\begin{array}{l}15 \\
(0.10)\end{array}$ & $\begin{array}{l}25 \\
(0.16)\end{array}$ & $\begin{array}{l}13 \\
(0.09)\end{array}$ & $\begin{array}{l}26 \\
(0.18)\end{array}$ & $\begin{array}{l}23 \\
(0.16)\end{array}$ \\
\hline Myocardial infarction as complication & 83 & 78 & 80 & 107 & 174 & 101 \\
\hline With new $Q$-wave & 22 & 11 & 8 & 13 & 15 & 5 \\
\hline Defined by troponin or CK & 58 & 66 & 55 & 79 & 132 & 93 \\
\hline Nonfemoral (radial) approach & 3084 & 4260 & 5834 & 5817 & 5580 & 6868 \\
\hline Switch to femoral during procedure & - & - & - & 256 & 366 & 551 \\
\hline Local radial artery complications & - & - & - & - & - & 33 \\
\hline Reversible neurologic complications & 19 & 14 & 17 & 7 & 11 & 24 \\
\hline Irreversible neurologic complications & 4 & 4 & 2 & 1 & 1 & 6 \\
\hline Vascular peripheral complication & 110 & 123 & 105 & 95 & 225 & 108 \\
\hline With surgery or transfusion & 17 & 32 & 18 & 15 & 25 & 23 \\
\hline With local injection of thrombin & 24 & 32 & 25 & 23 & 55 & 31 \\
\hline Adverse reactions to contrast media & 27 & 29 & 30 & 24 & 30 & - \\
\hline \multicolumn{7}{|c|}{$\begin{array}{l}\text { Austrian Questionnaire "Non-acute percutaneous coronary interventions PCl" [11] } \\
\text { cases; } n \text { pooled analysis } \\
\text { Striking differences in italics } \\
\text { "-" data not available } \\
\text { PCl percutaneous coronary intervention, CK Creatine (Phospho)Kinase }\end{array}$} \\
\hline
\end{tabular}

Table 6 Cardiac catheter interventions in Austria 2012-2017

\begin{tabular}{|c|c|c|c|c|c|c|}
\hline Year & 2012 & 2013 & 2014 & 2015 & 2016 & 2017 \\
\hline $\begin{array}{l}\text { Acute } \mathrm{PCl} \text { (interrupts routine program) } \\
\text { (intention to treat with } \mathrm{PCl} \text { ) }\end{array}$ & 7026 & 7148 & 7791 & 8084 & 8612 & 9553 \\
\hline Mortality acute overall (\%) & $\begin{array}{l}156 \\
(2.22)\end{array}$ & $\begin{array}{l}170 \\
(2.38)\end{array}$ & $\begin{array}{l}218 \\
(2.80)\end{array}$ & $\begin{array}{l}192 \\
(2.38)\end{array}$ & $\begin{array}{l}213 \\
(2.47)\end{array}$ & $\begin{array}{l}157 \\
(1.64)\end{array}$ \\
\hline PCl acute without shock & 6537 & 6754 & 7316 & 7648 & 7648 & 7867 \\
\hline Mortality PCI without shock (\%) & $\begin{array}{l}51 \\
(0.78)\end{array}$ & $\begin{array}{l}68 \\
(1.01)\end{array}$ & $\begin{array}{l}70 \\
(0.96)\end{array}$ & $\begin{array}{l}81 \\
(1.06)\end{array}$ & $\begin{array}{l}78 \\
(1.02)\end{array}$ & $\begin{array}{l}56 \\
(0.71)\end{array}$ \\
\hline PCl acute with shock & 489 & 394 & 475 & 436 & 467 & 318 \\
\hline Mortality PCI with shock (\%) & $\begin{array}{l}96 \\
(19.63)\end{array}$ & $\begin{array}{l}102 \\
(25.89)\end{array}$ & $\begin{array}{l}148 \\
(31.16)\end{array}$ & $\begin{array}{l}111 \\
(25.46)\end{array}$ & $\begin{array}{l}135 \\
(28.91)\end{array}$ & $\begin{array}{l}101 \\
(31.76)\end{array}$ \\
\hline Nonfemoral (radial) approach & 1319 & 1912 & 2389 & 3004 & 3567 & 3937 \\
\hline Switch to femoral during procedure & - & - & - & 144 & 186 & 145 \\
\hline Local radial artery complications & - & - & - & - & - & 29 \\
\hline Reversible neurologic complications & 10 & 7 & 6 & 4 & 5 & 5 \\
\hline Irreversible neurologic complications & 2 & 1 & 1 & 3 & 3 & 2 \\
\hline Vascular peripheral complication & 90 & 67 & 62 & 34 & 75 & 62 \\
\hline With surgery or transfusion & 19 & 17 & 10 & 9 & 12 & 9 \\
\hline With local injection of thrombin & 25 & 13 & 7 & 7 & 13 & 18 \\
\hline \multicolumn{7}{|c|}{$\begin{array}{l}\text { Austrian Questionnaire "Acute percutaneous coronary interventions" }=P C l \text { in suspected myocardial infarction } \\
\text { cases; } n \text { pooled analysis } \\
\text { Striking differences in italics } \\
\text { "-" Data Not Available } \\
P C / \text { percutaneous coronary intervention, Acute PCIPCI in patients that interrupt routine program }\end{array}$} \\
\hline
\end{tabular}

IIIa $(5.0 \%)$ or thrombin inhibitors (TI, $0.83 \%)$ is now extremely rare (Table 4, Fig. 6).

Reinterventions for chronic stent restenosis (REDOs) remain constant at $4.4 \%$ of PCI in reporting centers (in $2017 n=782$, in 2010: 4.6\%, Supplementary Table 2); however, the proportion of very late stent thrombosis as the cause of the reintervention is de- creasing, at 9.6\% of all REDO's in 2017 (2016: 11.0\%, 2015: 15.4\%) (Supplementary Table 2).

\section{Trends in puncture techniques}

Non-femoral (mostly radial) puncture techniques (Table 2, 3, 5 and 6) in diagnostic CA increased in absolute terms from $n=18,441$ (2013) to $n=34,627$ (2017) (Тa- 
Fig. 7 Percentage of PCls using Radial Access in Austria, 2011-2018

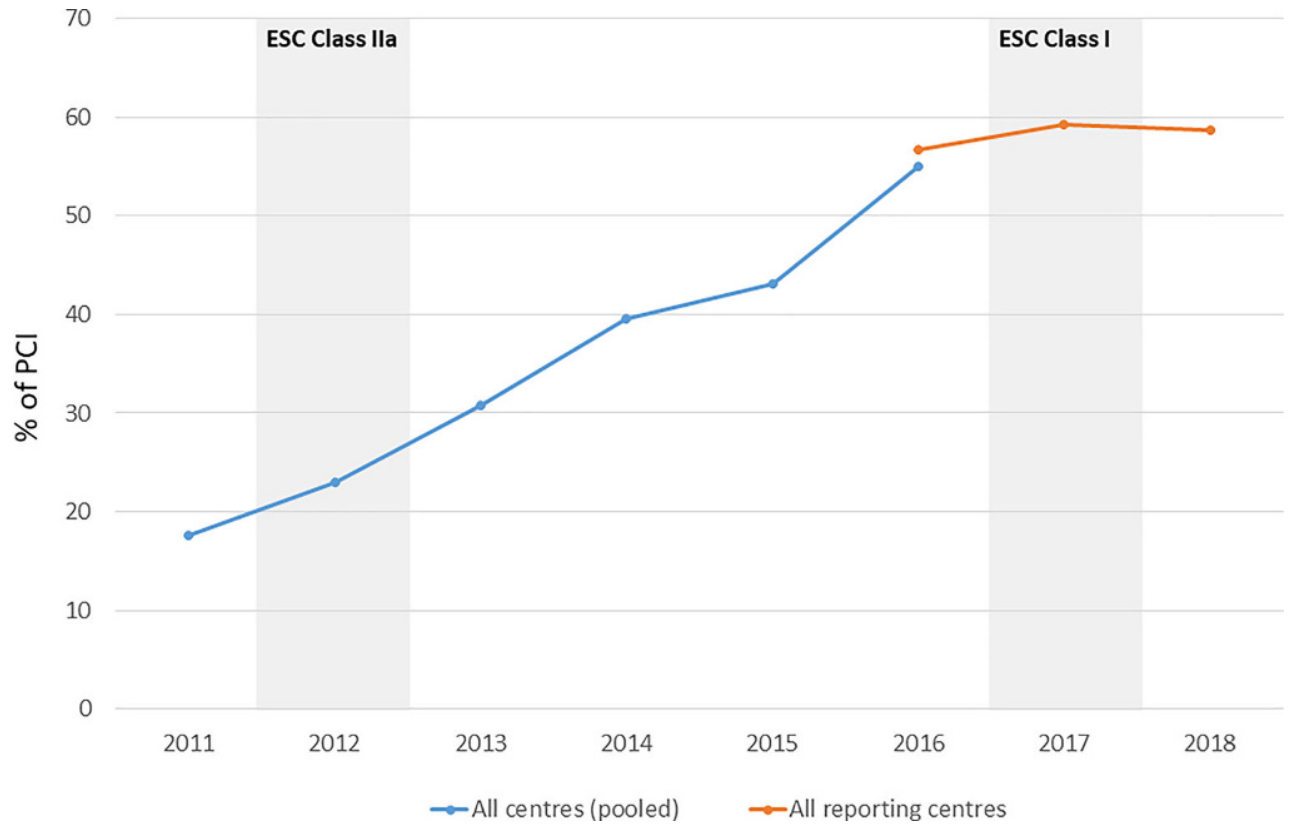

ble 2). During diagnostic CA, $6.4 \%$ required a switch from radial to femoral (Table 2), with $5.2 \%$ of those acute radial cases requiring a switch from radial to femoral during the procedure. Since 2016 there has been a plateau in the use of radial approach (Fig. 7). The number of ad hoc PCIs during diagnostic CA continues to decline $(84.4 \%$ in 2015 to $75.0 \%$ in 2017$)$.

Complications due to radial puncture techniques (Table 2, 3, 5 and 6) were first documented in 2017 [22]. Predictors of radial artery occlusions (RAO) are published by individual centers [22].

\section{Use of new intracoronary interventional devices}

The time of new devices and techniques (innovations) within CathLabs seems few and far between today $[23,24]$. For example, use of the drug eluting balloon (DEB), is now declining (Table 4). Declining use of biodegradable vascular scaffolds (BVS) accelerated since 2014. A similar reduction can be seen with catheter thrombectomies $(n=891)$ and intra-aortic balloon pumps $(n=53)$ (Table 4). Left atrial appendage closures (LAA closures), showed a slight renaissance in Austria in $2017(n=76)$ (Table 7).

\section{Extracoronary interventions}

The number of procedures on peripheral vessels, e.g. kidneys and legs remained constant, while the number of carotid procedures within the cardiac catheterization laboratories has decreased (Table 7).

Electrophysiology continued to increase in 2017 in all 21 performing centers (Fig. 4). Electrophysiological ablations ( $n=3640$, total) are well established and increasing, of which $n=1514$ were for atrial fibrillation (AF) and $n=396$ for ventricular arrhythmia (VT). Of the $n=2143$ pacemaker implantations within the
CathLabs $n=157$ were "leadless pacemakers", a real innovation pioneered in 2014 at an Austrian center, now spreading worldwide (Table 8).

In all 10 performing centers, increases are found in percutaneous valve implantations or valve replacements, e.g. TAVI/TAVR in $2017(n=1016)$, as well as in the MitraClip ( $n=139$ ) (Fig. 5; Table 7 ).

A visible phenomenon in 2017 are $n=2148$ cases with intracoronary (IC) devices (Table 3) but without following therapeutic intervention $(11.9 \%$ of PCI during 2017, Supplementary Table 2). This results in a rate of $42.4 \%(2148 / 5061$, Table 4$)$ of cases with IC devices (any) without following therapeutic intervention, such as pressure wire with or without adenosine (FFR; $n=3668$ ), IC ultrasound (IVUS; $n=755$ ), or optical coherence tomography (OCT; $n=638$ ) in reporting centers in 2017. In 2016 the percentage was higher, at 49.2\% (2532/5146; Table 4).

\section{Data quality}

The methods of ANCALAR have meant that data for benchmark parameters have been reported by $100 \%$ of clinics in each year the data were requested, generating a rich database. For a few specific parameters, particularly indicators of negative outcomes such as severe bleeding during CA or PCI, not all clinics report these data which could lead to underreporting if these outcomes are occurring but are not being reported in the registry. A description of missing data is available in Supplementary Table 2, which notes the exact number of clinics (out of the 34 possible) from which only complete data were pooled to calculate the respective indicator. ANCALAR provides the most comprehensive data concerning cardiac catheterization in Austria today, across all PCI capable health facilities operating in the country. 
Table 7 Percutaneous CathLab interventions and related procedures in Austria (2012-2017)

\begin{tabular}{|c|c|c|c|c|c|c|}
\hline Year & 2012 & 2013 & 2014 & 2015 & 2016 & 2017 \\
\hline Renal, iliac or leg artery intervention in cathlab & 559 & 475 & 551 & 593 & 816 & 706 \\
\hline Carotid artery intervention in cathlab & 70 & 55 & 52 & 56 & 65 & $49 \downarrow$ \\
\hline Mitral valvuloplasty & 42 & - & - & - & - & - \\
\hline MitraClip implantation & 51 & 62 & 89 & 91 & 123 & $139 \uparrow$ \\
\hline Transcatheter aortic valve implantation (TAVI) & 432 & 480 & 604 & 668 & 834 & $1016 \uparrow$ \\
\hline Transapical valve (reporting incomplete) & 29 & 35 & 26 & 55 & 46 & $133 \uparrow$ \\
\hline Transarterial valve & 403 & 445 & 578 & 613 & 788 & $881 \uparrow$ \\
\hline PFO/ASD/PDA closure by catheter & 193 & 191 & 218 & 217 & 218 & 198 \\
\hline Renal denervation $(P R D=R N D)$ & 151 & 144 & 58 & 29 & 14 & - \\
\hline Other valve interventions & - & - & - & - & 13 & 15 \\
\hline Left atrial appendix (LAA) closure & - & - & - & - & 57 & $76 \uparrow$ \\
\hline \multicolumn{7}{|c|}{$\begin{array}{l}\text { Austrian questionnaire "Non-coronary or non-cardiac interventions" } \\
\text { (cases; } n=; \text { pooled analysis). } \\
\text { Striking differences in italics. Striking changes from } 2016 \text { to } 2017 \text { are indicated with directional arrows } \uparrow \text { (increase) } \downarrow \text { (decrease) } \\
\text { PFO Persisting Foramen Ovale, ASD Atrial Septal Defect, PDA Persisting Ductus Arteriosus, PRD Percutaneous Renal Denervation } \\
\text { "-" or" Data Not Available }\end{array}$} \\
\hline
\end{tabular}

Table 8 Percutaneous CathLab interventions and related procedures in Austria (2012-2017)

\begin{tabular}{|c|c|c|c|c|c|c|}
\hline Year & 2012 & 2013 & 2014 & 2015 & 2016 & 2017 \\
\hline Myocardial biopsies & 180 & 226 & 292 & 303 & 340 & $356 \uparrow$ \\
\hline Diagnostic electrophysiology & 3087 & 3185 & 3417 & 3584 & 3742 & $3906 \uparrow$ \\
\hline Electrophysiological ablations & 3098 & 3019 & 3254 & 3313 & 3482 & $3640 \uparrow$ \\
\hline Ablation in atrial fibrillation (reported since 2013) & - & $142^{\mathrm{a}}$ & 1162 & 1238 & 1285 & $1514 \uparrow$ \\
\hline Ablation in ventricular rhythm disorders (reported since 2013) & - & $4^{\mathrm{a}}$ & 230 & 249 & 369 & $396 \uparrow$ \\
\hline DEVICE implantations (pacemakers) & 2109 & 2198 & 1932 & 2061 & 2102 & 2143 \\
\hline Leadless pacemaker & - & $4^{b}$ & 32 & 64 & 84 & $157 \uparrow$ \\
\hline \multicolumn{7}{|c|}{$\begin{array}{l}\text { Austrian questionnaire "Diagnostics and Electrophysiology" } \\
\text { cases; } n \text { pooled analysis } \\
\text { Striking differences in italics, Striking changes from } 2016 \text { to } 2017 \text { are indicated with directional arrows } \uparrow \text { (increase) } \downarrow \text { (decrease) } \\
\text { aincomplete response } \\
\text { "worldwide pioneer } \\
\text { "-" Data Not Available }\end{array}$} \\
\hline
\end{tabular}

\section{Discussion}

Austria currently ranks alongside the top countries in Europe in respect to CA and PCI use. As with other countries, complex and acute interventions are increasing year by year in Austria. STEMI-PCI is increasing year by year and now accounts for one fifth of all PCIs, this current trajectory will present logistical challenges given the need for complex cases to be assigned to experienced centers [24, 25].

With respect to international guidelines, Austria provides some interesting insights-guidelines are often slower in their reaction to new evidence than the daily practice of cardiologists. The use of the radial approach in Austria reflects this: over $50 \%$ of PCIs were conducted using TRA prior to the ESC classifying the evidence in support of the procedure as class I, in 2016 (Fig. 7); however, since 2016 TRA use has plateaued in Austria as cardiologists react to new evidence that the relative clinical benefits of TRA are less than previously thought, in spite of the current guidelines [23].
Registry data, by its nature, has strengths and weaknesses. ANCALAR has been collecting data on real world cardiology practice in Austria for over 30 years, enabling benchmarking and international comparisons. Personal communication with leading physicians in cathlabs across Austria has meant that year on year every center practicing interventional cardiology in Austria has submitted data to the ANCALAR. ANCALARs methods are transparent and standardized, with onsite audits, cross-validation of data where needed, and centralized data processing, ensuring high quality data that is comparable over time. Throughout each calendar year, leading physicians in all cathlabs offer feedback on ANCALAR, with annual meetings enabling personal discussion between cardiologists about adaptations to indicators and introduction of new indicators. ANCALAR is a valuable resource to cardiologists within both Austria and internationally, its integrity strengthened by its continued financial independence of any person or institution.

As expected with registry data, qualitative issues in definition and reporting make statistical analysis of 
mortality (Table 2, 3, 4 and 5) increasingly complex. For example, the classification of PCI in cardiogenic shock (ICD10: R57.0) leaves a lot of room for manoeuvre. Additionally, the decline of ad hoc PCIs in Austria may well be actually due to the discharge of a patient after radial diagnostics who are considered a "new" admission when a femoral instead of radial puncture for PCI is performed on a separate date. With respect to re-punctures, there are questions about whether switch to femoral access during PCI is also classified as re-punctures or not, leading to potential underreporting due to these qualitative definition issues.

Indeed, underreporting remains a key issue in registry data, not solely due to definitional issues. Of particular note is the potential underreporting and thus subsequent underestimation of mortality rates. It follows that it is is reasonable to expect that the low mortality rate for all acute PCI of $1.64 \%$ in 2017 is likely an underestimate due to underreporting and missing data. Many centers may only report mortality for acute PCI if deaths occur "on the cathlab table", which could also lead to the underestimation of mortality. Additionally, PCI complications are underreported; however, some centers in Austria as well as in Switzerland independently publish their complication rates [7, 18].

Registry data cannot provide answers to causal questions. For example, the link between decreasing peripheral vascular complications and decreasing application of GPI and TI.

Registries are necessarily limited in the amount and type of data they collect. The impact of periprocedural myocardial infarction (MI) is important (Table 2, 3 and 5), yet this area remains underdocumented in the ANCALAR [26]. Additionally, the distinction between restenosis due to chronic hyperplasia or late/very late stent thrombosis is not easily discernible from registry data, particularly given the data may not necessarily be recorded by the interventional physician [25, 27]; however, registry data are the key to highlight current trends in daily practice and provide evidence of the effects of changing practice. For example, there appears to be a decline in PCI for restenosis due to late stent thrombosis in Austria. Maybe the application of dual antiplatelet therapy (DAPT), even in all-comers, is now proving effective [28]. No restenosis is few and far between today [29].

Where feasible, specialist sub-registries are required to supplement registry data. For example, in Austria data on silent closures of radial arteries, higher technical and x-ray exposure and differential learning curves in radial puncture techniques are available in the special Austrian registry, (http://ptca.i-med.ac.at), which observes STEMI patients [30].

Policy and practice are influenced by cardiac registries. Guidelines can be slow to react to emerging evidence and changes in real world practice. Registries such as ANCALAR can both influence the construction of guidelines and enable cardiologists to under- stand the "sinn und unsinn" (sense and nonsense) of current guidelines. Moreover, registries such as ANCALAR hold a mirror up to all stakeholders in the world of cardiac intervention, from authorities to cardiologists making everyone more alert to changes in everyday practice. For example, during the autumn conference of the ÖKG working group, which took place on 1 December 2017, in response to new ANCALAR data it was decided that every physician in Austria performing acute PCI should master both the radial and femoral techniques. Indeed, sometimes in interventional cardiology, registries such as ANCALAR are the only and/or most up to date benchmark.

\section{Conclusion}

The most recent results from ANCALAR highlight that interventional cardiology in Austria is, in the main, in line with the top countries in Europe. However, some Austrian idiosyncrasies in response to new evidence and guidelines exist. Often, Austria reacts very early to new evidence and guidelines, as seen by trends in GPIIb/IIIa, radial access and direct thrombin inhibitors. Indeed Austria remains hesitant in adopting new devices, particularly those with niche applications such as aspiration thrombectomy, and avoids "hypes", such as biostents. Austria is often both ahead of the curve, adapting daily practice before new guidelines are released, whilst simultaneously proceeding with caution, particularly with respect to new devices.

The dynamic nature of cardiac catheterization and increasing number of complex cases has implications for cardiac registries, including ANCALAR. Quantitative changes in complication and mortality rates may in fact reflect qualitative changes in data reporting resultant of such dynamism, cardiac registers and the interpretation of their data need to continue to adapt in the face of such changes.

In conclusion our registry data show that Austria is another example of the difficulties of real life and science meeting in the world of interventional cardiology; with registry data careful interpretation is needed to identify artefacts and understand real differences in the practice of interventional cardiology [31].

Funding Open access funding provided by University of Innsbruck and Medical University of Innsbruck.

Conflict of interest V. Mühlberger, L. Kaltenbach, K. Bates and H. Ulmer declare that they have no competing interests.

Open Access This article is licensed under a Creative Commons Attribution 4.0 International License, which permits use, sharing, adaptation, distribution and reproduction in any medium or format, as long as you give appropriate credit to the original author(s) and the source, provide a link to the Creative Commons licence, and indicate if changes were made. The images or other third party material in this article are included in the article's Creative Commons licence, unless indicated otherwise in a credit line to the material. If material is not included in the article's Creative Commons licence and 
your intended use is not permitted by statutory regulation or exceeds the permitted use, you will need to obtain permission directly from the copyright holder. To view a copy of this licence, visit http://creativecommons.org/licenses/by/4.0/.

\section{References}

1. World Health Organization. Fact sheet on cardiovascular diseases 2017. 2019. https://www.who.int/en/newsroom/fact-sheets/detail/cardiovascular-diseases-. Accessed 13 May 2019.

2. Task Force Members, Montalescot G, Sechtem U, et al. 2013 ESC guidelines on the management of stable coronary artery disease: the Task Force on the management of stable coronary artery disease of the European Society of Cardiology. Eur Heart J. 2013;34(38):2949-3003.

3. Muller RL, Sanborn TA. The history of interventional cardiology: cardiac catheterization, angioplasty, and related interventions. Am Heart J. 1995;129(1):146-72.

4. Writing Committee Members, Bhatt DL, Drozda JP Jr, Shahian DM, et al. ACC/AHA/STS Statement on the Future of Registries and the Performance Measurement Enterprise A Report of the American College of Cardiology/American Heart Association Task Force on Performance Measures and The Society of Thoracic Surgeons. Circ Cardiovasc Qual Outcomes. 2015;8:634-48. https://doi.org/10.1161/HCQ. 0000000000000013.

5. Mühlberger V, Kobel C, Kaltenbach L, Pachinger O. Austrian National CathLab Registry (ANCALAR): Cardiac Catheterization, Coronary Angiography (CA) and PCI in Austria During the Year 2011 (Registry Data with Audit including 2012). Wien Klin Wochenschr. 2013;125:736-49.

6. Mühlberger V. Entwicklungsstand der Interventionellen Kardiologie in Österreich. Wien Med Wochenschr. 1992;15(16):324-30.

7. Schuell S, Cook St, Wenaweser P. Interventional Cardiology in Switzerland. Figures for the Year 2016 and 2017, und CookSt. persönlicheKommunikation 17. http://www.ptca. ch/DOCS_PUBLIC/ptca_statistics_2017.pdf. Accessed $12 / 08 / 2019$

8. Meinerz T, Katus HA, Vestweber M. Deutscher Herzbericht Dezember 2017. Frankfurtam Main: DeutscheHerzstiftung e.V. 2017. www.herzstiftung.de/herzbericht. Accessed $06 / 06 / 2019$

9. Bruckenberger E. Herzbericht 2010 mit Transplantationschirurgie; 23. Bericht. Sektorübergreifende Versorgungsanalyse zur Kardiologie und Herzchirurgie in Deutschland sowie vergleichende Daten zur Kardiologie aus Österreich und der Schweiz. Eigenverlag. http://www.bruckenberger. de. Accessed 12/08/2019

10. Meier B. Switzerland reports "courant normal" in interventional cardiology, 30 years after inventing it. Kardiovask Med. 2010;13(1):3-5.

11. Austrian National CathLab Registry (ANCALAR). 2018. https://iik.i-med.ac.at/index.php?param $=2017$. Accessed $13 / 01 / 2020$

12. Flynn MR, Conor B, CosíoFG, GittAK, Wallentin L, KearneyP et al. The Cardiology Audit and Registration Data Standards (CARDS), European data standards for clinical cardiology practice. Eur Heart J. 2005;26(3):308-13. https://doi.org/ 10.1093/eurheartj/ehi079.

13. Mühlberger V, Kaltenbach L, Kobel C, Pachinger O. Herzkathetereingriffe in Österreich im Jahr 2012 (mit Audit bis 2013). J Kardiol. 2013;21(2014):76-80.

14. Muehlberger V, Kaltenbach L, Ulmer H, Pachinger O. Herzkathetereingriffein Oesterreich im Jahr 2013 (mit Audit 2014). J Kardiol. 2015;22(1-2):22-6.
15. Mühlberger V, Kaltenbach L, Ulmer H. Herzkathetereingriffe in Österreich im Jahr 2014 (mit Audit bis 2015). JKardiol. 2016;23:7-12.

16. Muehlberger V, Kaltenbach L, Ulmer H. Herzkathetereingriffe in Oesterreich im Jahr 2015 (mit Audit bis 2016). JKardiol. 2017;24(1-2):7-12.

17. Mühlberger V, Kaltenbach L, Ulmer H. Herzkathetereingriffe in Österreich im Jahr 2016 (mit Audit 2017). J Kardiol. 2018;25(1-2):9-15. J.Kardiol online since 17.11.2017.

18. Mühlberger V, Kaltenbach L, Ulmer H. Herzkathetereingriffe in Österreich im Jahr 2017 (mit Audit 2018). J Kardiol. 2019;26(1-2):10-26. J.Kardiol online since 25.10.2018.

19. Maier W, Windecker S, Lablanche JM, Mühlberger V, Wijns W, Meier B, et al. The European Registry of Cardiac Catheter Interventions 1996. Eur Heart J. 2001;22:373-7.

20. Krumholz HM, Anderson JL, Brooks NH, et al. ACC/AHA clinical performance measures for adults with ST-elevation and non-ST-elevation myocardial infarction: a report of the American College of Cardiology/American Heart Association Task Force on Performance Measures (Writing Committee to Develop Performance Measures on ST-Elevation and Non-ST-Elevation Myocardial Infarction). J Am Coll Cardiol. 2006;47:236-65.

21. Durko AP, Osnabrugge RL, Van Mieghem NM, et al. Annual number of candidates for transcatheter aortic valve implantation per country: current estimates and future projections. Eur HeartJ.2018;39:2635-42.

22. Madreiter P, Podczeck-Schweighofer A, Christ G. Predictors of radial artery occlusion (RAO) after transradial catheterization: Prospective single centre registry with 1000 consecutive patients. Wien Klin Wochenschr. 2017;129(suppl 1):2.

23. Schernthane C, Hammerer $M$, Harb S, Heigert $M$, Hoellinger K, Lassnig E, et al. Radial versus femoral access site for percutaneous coronary intervention in patients suffering acute myocardial infarction A randomized prospective multicenter trial. Wien Klin Wochenschr. 2018; https://doi.org/10.1007/s00508-017-1260-5.

24. Byrne RA, Kastrati A. Unmet aspirations - where to now for catheter thrombectomy? NEngJ Med. 2013;369:1649-50.

25. Neumann FJ, Gick M. Direct stenting in ST-elevation myocardial infarction: convenient, but not improving outcomes. Eur Heart J. 2018;39:2480-3.

26. Thygesen K, Jaffe AS. The prognostic impact of periprocedural myocardial infarction and injury. Eur Heart J. 2018;39:1110-2.

27. Bhatt DL. Assessment of stable coronary lesions. N Engl J Med. 2017;376(19):1879-81.

28. Mauri L, Kereiakes DJ, Yeh RW, Driscoll-Shempp P, Cutlip DE, Steg PG, et al. Twelve or 30 months of dual Antiplatelet therapy after drug-eluting stents. NEngl J Med. 2014;371(23):2155-66.

29. Kereiakes DJ. Healing by design: in vivo insights following contemporary stent deployment. Eur Heart J. 2018;39:2457-9.

30. Österreichische Kardiologische Gesellschaft (ÖKG). Akut PTCA Register der ÖKG. 2019. http://ptca.i-med.ac.at. Accessed 31 Jan 2019.

31. Meier B. Interventional cardiology, where real life and science do notnecessarily meet. Eur Heart J. 2016;37:2014-9.

Publisher's Note Springer Nature remains neutral with regard to jurisdictional claims in published maps and institutional affiliations. 